\title{
Insulin sensitizing effect as possible mechanism of the antidiabetic properties of the methanol and the aqueous extracts from the trunk bark of Ceiba pentandra
}

\author{
Fofie KC ${ }^{1,2}$, Khatekaye $\mathrm{S}^{2}$, Nguelefack-mbuyo $\mathrm{PE}^{1}$, Kamanyi $\mathrm{A}^{1}$, Kamble $\mathrm{B}^{3}$, Chauhan $\mathrm{N}^{4}$, Singh $\mathrm{V}^{2}$ and Nguelefack TB $^{1 *}$ \\ ${ }^{1}$ Laboratory of Animal Physiology and Phytopharmacology, Faculty of Science, University of Dschang, P.O. Box 67, Dschang, Cameroon \\ ${ }^{2}$ School of Biological Sciences and Biotechnology, Institute of Advanced Research, Koba Institutional Area, Gandhinagar-382426, India \\ ${ }^{3}$ Department of Natural Products, National Institute of Pharmaceutical Education and Research (NIPER) Ahmedabad, Palaj, Gandhinagar-382355, India \\ ${ }^{4}$ Karnavati School of Dentistry, Karnavati University, Gandhinagar-382422, India
}

\begin{abstract}
The objective of this study was to determine the antidiabetic mechanism of the aqueous (AE) and methanol (ME) extracts from Ceiba pentandra. The Oral Glucose Tolerance Test was performed in normal rats pretreated with $\mathrm{AE}$ and $\mathrm{ME}$ at doses of 75 and $150 \mathrm{mg} / \mathrm{kg}$. The effects of these extracts were further evaluated on hepatic glycogenolysis, gluconeogenesis, and glycogen synthesis using HepG2 cells in presence of insulin. The ability of the extracts to inhibit hemoglobin glycation was also determined. Results from OGTT show that $\mathrm{AE}$ and ME significantly reduced hyperglycemia in a dose-dependent manner. AE and ME significantly inhibited gluconeogenesis by $8.89 \%$ and $15.59 \%$ respectively. Only ME in presence of insulin, significantly increase glycogen synthesis (29.65\%). AE and ME also significantly inhibited hemoglobin glycation by 11 and $16 \%$. These results suggest that $\mathrm{AE}$ and $\mathrm{ME}$ antidiabetic effects may at least partially result from the inhibition of gluconeogenesis, promotion of glycogen synthesis and inhibition of hemoglobin glycation.
\end{abstract}

\section{Introduction}

Diabetes is a serious public health concerns today, as it represents a significant cause of morbidity and mortality in populations. In respect to this, the International Diabetes Federation estimates that there are approximately 425 million diabetics worldwide and that nearly 4 million deaths were directly caused by diabetes in 2017 [1].

Type 2 diabetes (T2D) is characterized by chronic hyperglycemia secondary to reduction in insulin action and/or production. Besides this, T2D is also characterized by postprandial hyperglycemia (PPHG) [2]. Essentially, it is the hepatic insulin resistance and the subsequent production of glucose by the liver that represents the main factor responsible for PPHG [3]. Hyperglycemia in turn causes systemic damages, through such mechanisms as glycation of molecules. The end stage of this glycation leads to formation of AGEs, which initiate cell dysfunctions leading to worsening of diabetes [4].

Many drugs are now available to help keep blood glucose at a normal level. There are those that promote the use of insulin, those that limit sugar digestion, and those that promote insulin secretion. However, most of these available drugs are too specific and therefore necessitate their association which has as consequence, the overlapping of side effects with the patient condition. These limitations give the rational for the search for multiple target antidiabetic low toxic medications.

In order to palliate these limitations, our focus was directed towards Ceiba pentandra, a plant of the Cameroonian flora which has shown antidiabetic effects [5]. But so far, no probable mechanism of action has been clearly determined. The present study was therefore designed to determine the effect of the methanol and aqueous extracts from C. pentandra on hepatic glucose production and glycogen storage. In addition, the capacity of these extracts to inhibit protein glycation was also evaluated.

\section{Material and methods}

\section{Animal}

Male Wistar rats aged 3 months were used for in vivo study. They had free access to food and drinking water. The rats were acclimatized for 1 week, in group of 3 in cages and in room lighten with daylight, before the start of the experiment. Upon the experiment, they were starved for 14 hours.

\section{Cell}

HepG2 human liver cells were used for the in vitro testing. They were obtained from the National Center for Cell Science (NCCS, Ganeshkhind, Pune, India). These cells were cultured at $37^{\circ} \mathrm{C}$ in humidified $5 \% \mathrm{CO}_{2}$ milieu. They were grown in Dulbecco's Modified Eagle Medium (DMEM) supplemented with $10 \%(\mathrm{v} / \mathrm{v})$ fetal bovine serum (FBS), $100 \mu \mathrm{g} / \mathrm{ml}$ of penicillin and $10 \mu \mathrm{g} / \mathrm{ml}$ streptomycin. The confluent HepG2 cells were detached and separated with trypsin/EDTA

${ }^{\star}$ Correspondence to: Télesphore Benoît NGUELEFACK, Laboratory of Animal Physiology and Phytopharmacology, Faculty of Science, University of Dschang, P.O. Box 67, Dschang, Cameroon, E-mail: nguelefack@yahoo.fr

Key words: gluconeogenesis, glycogenolysis, glycogen synthesis, anti-glycation, ceiba pentandra

Received: November 02, 2018; Accepted: November 20, 2018; Published: November 23, 2018 
solution and suspended at the density of $10^{6}$ cells per well in a 24 -well plate.

\section{Plant material}

The fresh bark from the trunk of Ceiba pentandra was harvested in Yaoundé (Center region Cameroon) in 2016, dried and grounded. On the one hand, two hundred grams (200 g) of powder was macerated in 2 litres of distilled water and the mixture was boiled for about 20 minutes. After filtration, the liquid obtained was evaporated in an oven at $45 \pm 1^{\circ} \mathrm{C}$ for 72 hours. The resulting powder (aqueous extract) was stored at $2^{\circ} \mathrm{C}$ until use. On the other hand, two hundred grams of powder was macerated in 2 litres of methanol for 48 hours. After filtration, the liquid obtained was evaporated on a rotary evaporator. The resulting concentrate was then evaporated in an oven at $40 \pm 1^{\circ} \mathrm{C}$ for 24 hours. The paste obtained (methanol extract) was stored at $2^{\circ} \mathrm{C}$ until use.

\section{Chemicals}

Methanol, DMEM, FBS, penicillin, streptomycin, trypsin, EDTA, $\mathrm{NaOH}$, sodium hydrogen phosphate, sodium dihydrogen phosphate, Tris, bovine serum albumin (BSA), Coomassie blue were obtained from Himedia. Insulin, dexamethasone, glucose, glucagon, glycerol, DMSO, glibenclamide were purchased from Sigma.

\section{Methods}

\section{Oral glucose tolerance tests}

Three-month-old adult animals were used for this experiment. After 14 hours of fasting, the blood glucose levels of the rats were measured using a blood glucose meter and strips from Accu-Check ${ }^{\circ}$ Active brand. Then, the animals were divided in groups of 6 rats and treated as follows:

\section{Group 1: Distilled water/5\% DMSO solution (10 ml/kg, per os)}

Group 2: Glibenclamide (1 mg/kg, oral)

Group 3: Aqueous extract ( $75 \mathrm{mg} / \mathrm{kg}$, per os)

Group 4: Aqueous extract (150 mg/kg, per os)

Group 5: Methanol extract (75 mg/kg, per os)

Group 6: Methanol extract (150 mg/kg, per os)

One hour after administration of these different treatments, the animals received a glucose load ( $3 \mathrm{~g} / \mathrm{kg}$, per os). Glucose levels were measured again at 30, 60, 90 and 120 minutes after carbohydrate administration. Glibenclamide was used as reference drug.

\section{Evaluation of the effect of extracts on hepatic gluconeogenesis}

The effect of Ceiba pentandra extracts on gluconeogenesis was measured by incubating HepG2 cells in 24-well plates at a density of $10^{6} /$ well at $37^{\circ} \mathrm{C}$ in a humidified atmosphere $(5 \% \mathrm{CO} 2)$. After 24 hours of pre-culture, the HepG2 cells were treated with or without extracts of Ceiba pentandra $(10-30-100 \mu \mathrm{g} / \mathrm{ml})$ and insulin $(5 \mathrm{nM}$ or $50 \mathrm{nM})$ in culture medium at low glucose concentration $(5.5 \mathrm{mM})$ and without serum for $6 \mathrm{~h}$. The HepG2 cells were then washed twice with PBS to remove the glucose and incubated for $3 \mathrm{~h}$ under stimulation with glucagon $(100 \mathrm{nM})$ and dexamethasone $(10 \mathrm{nM})$, in an experimental glucose production medium (DMEM without glucose and without phenol red, containing $10 \mathrm{mM}$ glycerol, $\mathrm{pH}$ 7.4). At the end of this incubation period, glucose concentration was determined in samples. The latter was normalized with the concentration of proteins determined using Bradford's reagent.

\section{Evaluation of the effect of extracts on hepatic glycogenolysis}

The effect of Ceiba pentandra extracts on hepatic glycogenolysis was measured in vitro. Briefly, HepG2 cells were plated at a density of $10^{6}$ cells/well in 24-well plates and incubated in a glucose-enhanced DMEM ( $25 \mathrm{mM})$ medium for 24 hours. The cells were then washed twice with PBS and then incubated with $1 \mathrm{ml}$ of DMEM in the absence of glucose, glutamine and pyruvate, but containing $100 \mathrm{nM}$ glucagon in the presence or absence of $C$. pentandra extracts $(10-30-100 \mu \mathrm{g} / \mathrm{ml})$ and insulin $(5 \mathrm{nM}, 50 \mathrm{nM})$. Glycogenolysis was estimated by the quantity of glucose in the incubation medium. The glucose content in the medium was determined after $45 \mathrm{~min}$ incubation and the concentration was normalized with that of cellular proteins determined using Bradford's reagent.

\section{Evaluation of the effect of extracts on hepatic synthesis of glycogen}

The HepG2 cells were plated at a density of $10^{6}$ cells/well in 24 -well plates and then exposed to $C$. pentandra extracts $(10-30-100 \mu \mathrm{g} / \mathrm{ml})$ and/or insulin $(5 \mathrm{nM}, 50 \mathrm{nM})$ for $6 \mathrm{~h}$ in glucose-DMEM medium (11.1 $\mathrm{mM}$ glucose). After the incubation period, the cells were collected and lysed. In lysates the glycogen content was measured and normalized with the protein concentration determined using Bradford's reagent.

\section{Evaluation of the inhibitory effect extracts on protein glycation}

Hemolysate was prepared following Asgary et al. [6] as reported by Adisa et al. [7] based on the principle of hypotonic lysis. From the procedure, the red blood collected were washed thrice with $9 \%$ $\mathrm{NaCl}$ solution and 1 volume of red blood cells suspension was lysed with 2 volumes of $0.01 \mathrm{M}$ phosphate buffer, $\mathrm{pH} 7.4$ and 0.5 volume of carbon tetrachloride. The hemolysate was then freed from the debris by centrifugation at $2300 \mathrm{rpm}$ for $15 \mathrm{~min}$ at room temperature. The haemoglobin rich fraction (upper layer) was separated and dispensed into sample bottle for use.

To $1 \mathrm{ml}$ of a hemoglobin solution was added $5 \mu \mathrm{l}$ of gentamycin $(50 \mu \mathrm{g} / \mathrm{ml})$ and $25 \mu \mathrm{l}$ of gallic acid or extracts at concentrations ranging from 1 to $300 \mu \mathrm{g} / \mathrm{ml}$. The reaction was initiated by adding $1 \mathrm{ml}$ of $2 \%$ fructose prepared in phosphate buffer $(\mathrm{pH} 7.4,0.01 \mathrm{M})$ in the dark and at room temperature. The absorbances of glycated hemoglobin after 24 hours and 72 hours of incubation were colorimetrically determined at $443 \mathrm{~nm}$ as previously described by Adisa et al. [7]. The percentage of glycated hemoglobin formed was finally calculated according to the following formula:

$\%$ HbAlc $=(($ HbAlc control - HbAlc extracts $) / \mathrm{HbA} 1 \mathrm{c}$ control $)$ $\times 100$

\section{Ethical considerations}

Experimental protocols used in this study (Laboratory of Animal Physiology and Phytopharmacology, Department of Animal Biology, University of Dschang-Cameroon) were carried out according to the standard ethical guidelines for laboratory animal care and care in the European Community guidelines; EEC Directive 2010/63/EEC, of the 22nd September 2010 [8]. 


\section{Statistical analyses}

The data were analyzed using Graph Pad Prism software version 5.01. The results obtained were expressed as an average plus or minus Standard Error over the Mean (SEM). The one- and two-way analysis of variance (ANOVA) followed by the post-test of Turkey and Bonferroni respectively were used to analyze the data. The differences were considered significant when the probability threshold $\mathrm{p}$ was less than 0.05 .

\section{Results}

\section{Effect of Ceiba pentandra extracts on oral glucose tolerance} in normal animals

The results obtained from this experiment show that all tested substances considerably increased the tolerance of rats to glucose (Figure 1A). However, it should be noted that at time 120 minutes, glibenclamide reduced the initial blood glucose level by $18.4 \mathrm{mg} / \mathrm{dl}$. When comparing the areas under the curve (AUC), glibenclamide reduces the hyperglycemia by $57.30 \%$ whereas the aqueous and methanolic extracts of $C$. pentandra at the dose of $75 \mathrm{mg} / \mathrm{kg}$ respectively reduced the parameter by $22.55 \%$ and $40.54 \%$; and by $43.41 \%$ and $53.53 \%$ at the dose of $150 \mathrm{mg} / \mathrm{kg}$ (Figure 1B). The methanol extract was more active than the aqueous extract.

\section{Effect of Ceiba pentandra extracts on gluconeogenesis}

The results concerning the inhibition of hepatic glucose production from substrates other than glycogen are presented in Figure 2. The results from this experiment show that the most important effects of the extracts were obtained at the concentration of $100 \mu \mathrm{g} / \mathrm{ml}$. In comparison to insulin $(5 \mathrm{nM})$ alone, the combination of insulin with methanolic extract or insulin with aqueous extract respectively inhibited by $14.59 \%$ $(\mathrm{p}<0.001)$ (Figure $2 \mathrm{~A})$ and $8.89 \%(\mathrm{p}<0.01)$ (Figure $2 \mathrm{~B})$ the rate of hepatic glucose production.

\section{Effect of Ceiba pentandra extracts on glycogenolysis}

The results on the capacity of $C$. pentandra extracts to potentiate the insulin-inhibiting effect on glycogenolysis are presented in Figure 3. Although the combination of methanolic and aqueous extracts at the concentration of $100 \mu \mathrm{g} / \mathrm{ml}$ with insulin $(5 \mathrm{nM})$ reduced glycogen lysis by $14.53 \%$ (Figure $3 \mathrm{~A}$ ) and $7.48 \%$ (Figure $3 \mathrm{~B}$ ), respectively, the effects of the combinations were not significant as compared to the effect of insulin $(5 \mathrm{nM})$ alone.

\section{Effect of Ceiba pentandra extracts on glycogen synthesis}

The insulin-sensitizing effect of Ceiba pentandra extracts on glycogen synthesis is presented in Figure 4. It appears that the maximum effects were obtained at the concentration of $100 \mu \mathrm{g} / \mathrm{ml}$. When
A
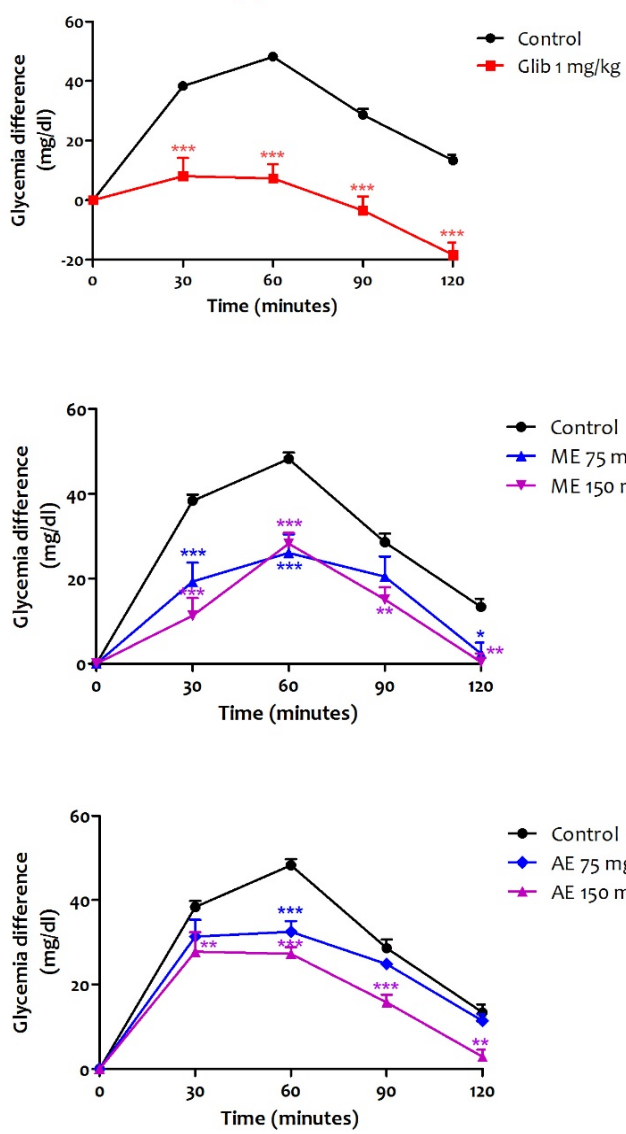

B
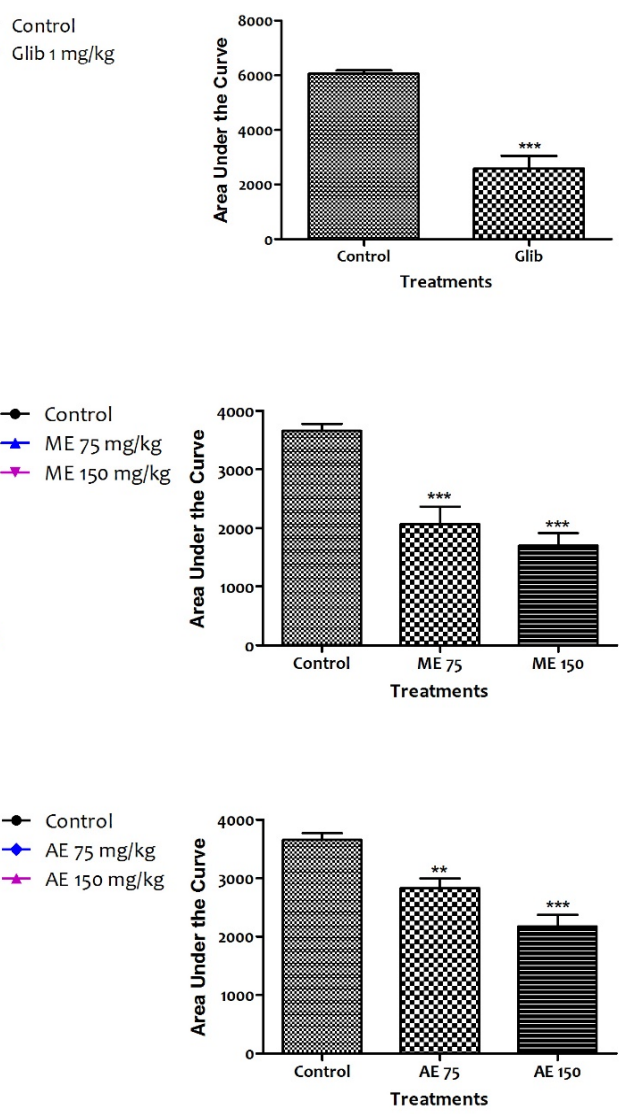

Figure 1. Glycemic lowering effects the aqueous and methanol extracts of Ceiba pentandra on glucose tolerance test. A: represents glycemic variation during the experiment. B: represents area under the curve (AUC) of glycemic variations. Values are expressed as mean $\pm \mathrm{SEM} ; * * \mathrm{p}<0.01, * * * \mathrm{p}<0.01$, with respect to control group. ME: methanol extract, AE: aqueous extract, Glib: glibenclamide 
A

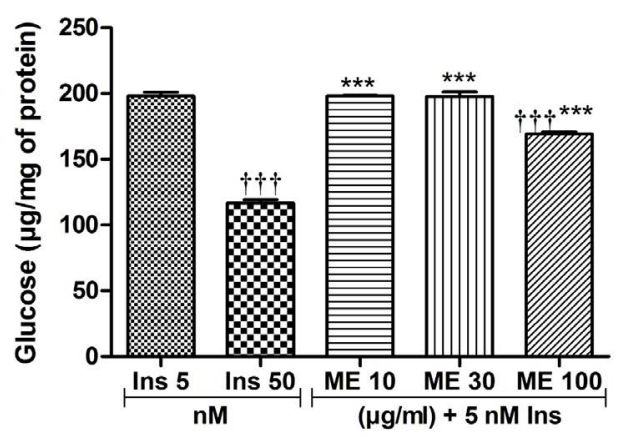

B

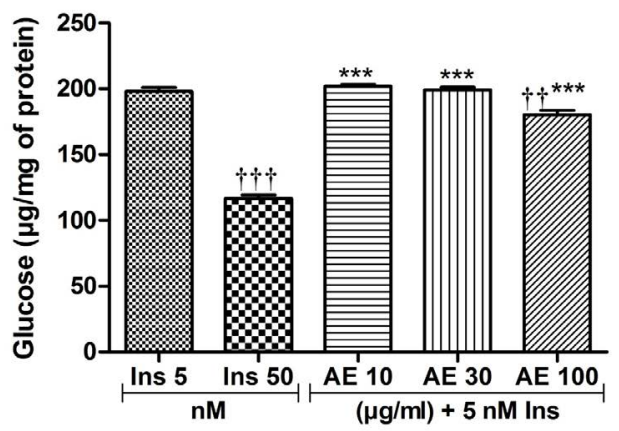

Figure 2. Insulin sensitizing effect of the methanol (A) and aqueous (B) extracts of Ceiba pentandra on gluconeogenesis. Values are expressed as mean $\pm \mathrm{SEM}$; $* *$ p $<0.01$, with respect to Ins $50 \mathrm{nM} . \dagger \dagger \mathrm{p}<0.01, \dagger \dagger \uparrow \mathrm{p}<0.001$, with respect to Ins $5 \mathrm{nM}$. ME: methanol extract, AE: aqueous extract, Ins: insulin

A

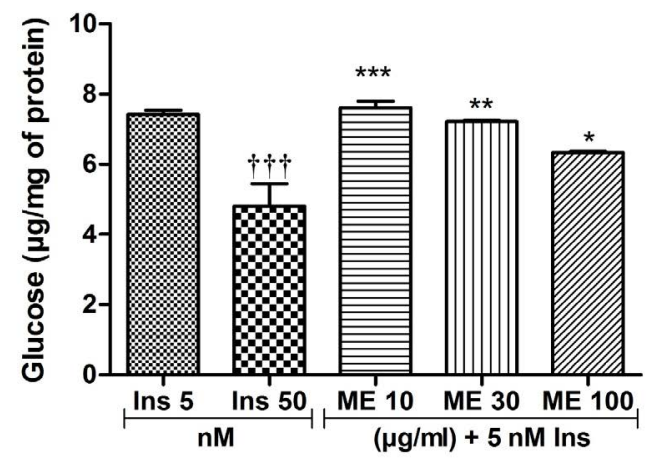

B

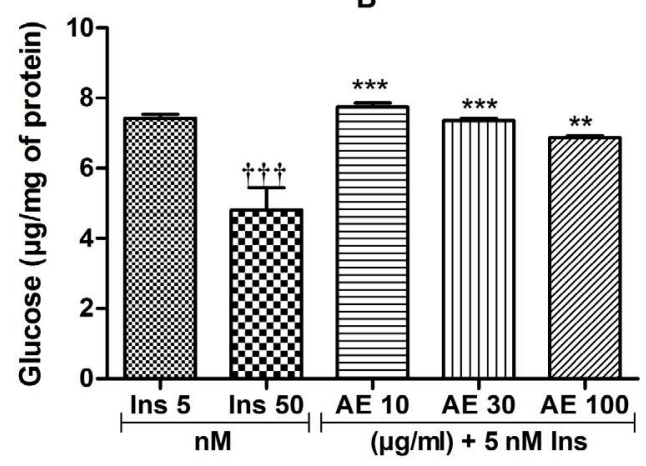

Figure 3. Insulin sensitizing effect of the methanol (A) and aqueous (B) extracts of Ceiba pentandra on glycogenolysis. Values are expressed as mean \pm SEM; ${ }^{*}<0.05 ; * * p<0.01$, ${ }^{* * *} \mathrm{p}<0.01$, with respect to Ins $50 \mathrm{nM}$. $\dagger \dagger \mathrm{p}<0.001$, with respect to Ins $5 \mathrm{nM}$. ME: methanol extract, AE: aqueous extract, Ins: insulin 
compared to insulin $(5 \mathrm{nM})$ alone, the combination of insulin $(5 \mathrm{nM})$ and methanolic extract $(100 \mu \mathrm{g} / \mathrm{ml})$ (Figure $4 \mathrm{~A})$ increased the amount of intracellular glycogen by $29.65 \%(\mathrm{p}<0.01)$, while the combination of insulin with aqueous extract $(100 \mu \mathrm{g} / \mathrm{ml})$ resulted in a $13.45 \%$ increase in intrahepatic glycogen levels (Figure 4B).

\section{Effect of Ceiba pentandra extracts on hemoglobin glycation}

The results obtained from the hemoglobin glycation test are shown in Figure 5. It was observed that only gallic acid at the concentration of $300 \mu \mathrm{g} / \mathrm{ml}$ was able to inhibit the hemoglobin glycation after 24 hours of incubation. Gallic acid induced a significant inhibition of $49 \%$ as compared to control (Figure 5A). After 72 hours of incubation, all the substances tested had a concentration-dependent effect on the glycation reaction. As such, the formation of glycated hemoglobin was inhibited by $26 \%$ with gallic acid $(p<0.001), 16 \%$ with the methanol extract $(\mathrm{p}<0.001)$ and $11 \%$ with the aqueous extract $(\mathrm{p}<0.001)$ (Figure $5 B)$.

\section{Discussion}

The significant increase of glucose level in the body as observed during diabetes is a condition that substantially influences the genesis of oxidative molecules, the formation of advanced glycation end products and the occurrence of end-tissue damages. In order to verify that the extracts from Ceiba pentandra have antihyperglycemic properties, the glucose tolerance test was undertaken. The results show that indeed these extracts improve the tolerance of animals to glucose by increasing the rate of disposal of this metabolic fuel. These results corroborate those of Satyaprakash et al. [9] who showed that the ethanolic extract

A

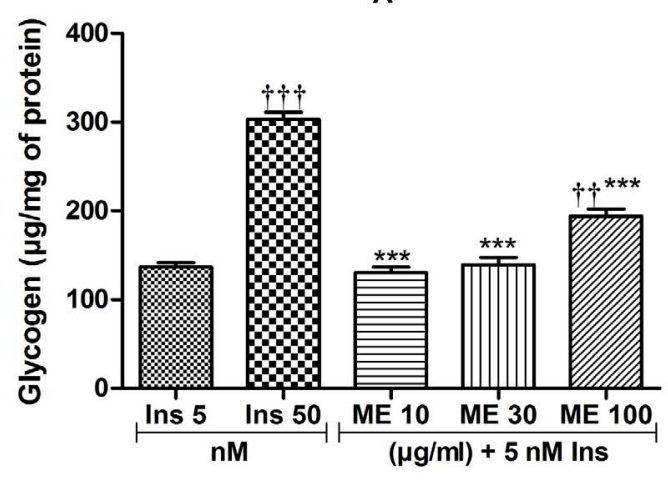

B

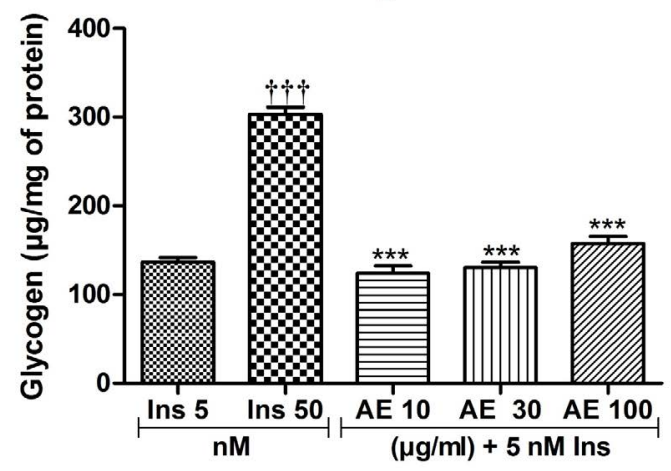

Figure 4. Insulin sensitizing effect of the methanol (A) and aqueous (B) extracts on glycogen synthesis. Values are expressed as mean \pm SEM; $* * * p<0.01$, with respect to Ins $50 \mathrm{nM} . \dagger \dagger \mathrm{p}<0.01, \uparrow \dagger \uparrow \mathrm{p}<0.001$, with respect to Ins $5 \mathrm{nM}$. ME: methanol extract, $\mathrm{AE}$ : aqueous extract, Ins: insulin
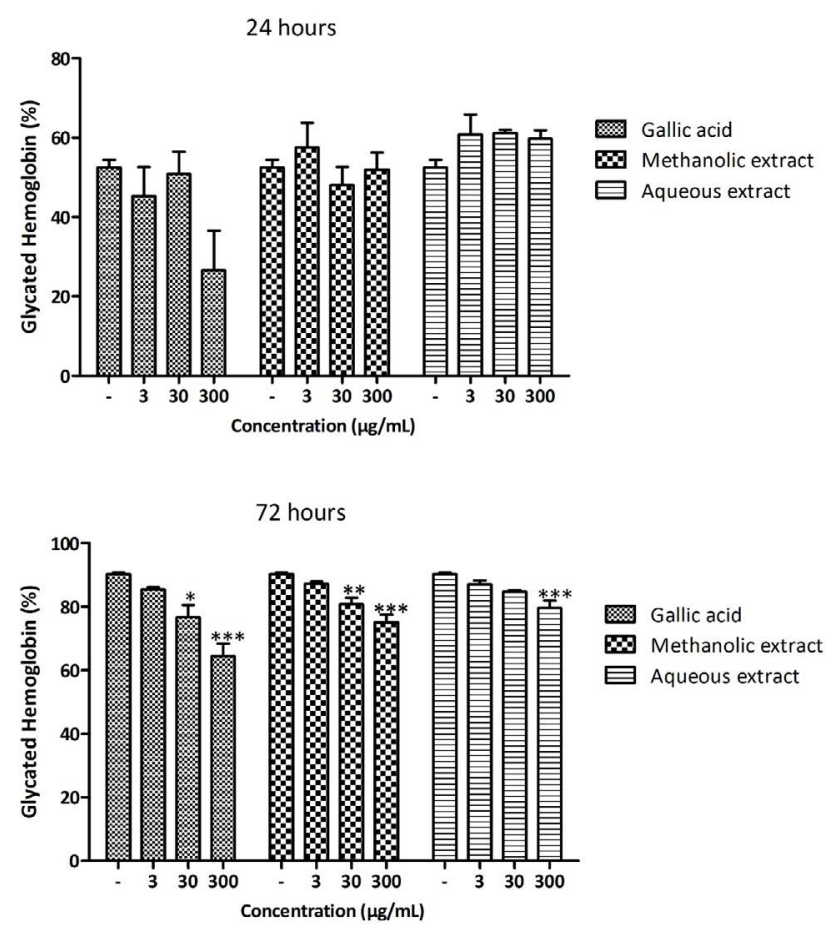

Figure 5. Inhibitory effect of the methanol and the aqueous extracts of Ceiba pentandra on fructose-induced hemoglobin glycation. Values are expressed as mean $\pm \mathrm{SEM} ;{ }^{*} \mathrm{p}<0.05$ $* * \mathrm{p}<0.01, * * * \mathrm{p}<0.01$, with respect to the untreated group (-)

of the bark of the trunk of Ceiba pentandra increased glucose tolerance in normal and diabetic rats. Thereafter, the mechanism through which this activity is achieved was evaluated.

The ability of extracts to inhibit hepatic glucose production was determined by evaluating their effect on gluconeogenesis and glycogenolysis. The results obtained showed that in both cases, the suppressive effect of insulin was greater in the presence of the extracts than insulin alone, although this potentiation was more powerful on gluconeogenesis than on glycogenolysis. The methanolic extract was more active than the aqueous extract. Indeed, several studies have clearly shown that hepatic glucose production during fasting periods in diabetes is mainly due to the increase in gluconeogenesis, the glycogenolysis remaining unchanged [10]. Results obtained by Fofié et al. [5] have shown that extracts from Ceiba pentandra prevented glycemic and lipid dysregulation induced by dexamethasone. This glucocorticoid increases the availability of neoglucogenic substrates, induces liver resistance to insulin action leading to hepatic glucose production, and stimulates the release of glucagon resulting in activation of glycogenolysis and gluconeogenesis [11]. It is therefore clear that extracts from Ceiba pentandra prevent diabetic hyperglycemia by suppressing hepatic glucose production. This is being achieved by potentiating the action of insulin, or by acting directly on the signaling pathways involved [12].

The second mechanism evaluated was the ability of the extracts to promote glucose storage by hepatocytes in the form of glycogen. Only the methanolic extract could actually induce a significant increase in glycogen synthesis. The importance of this activity lies in the fact that before reaching the systemic circulation, the glucose ingested must cross a double filter, intestinal then hepatic: $25 \%$ of the glucose ingested is used or stored (liver) at these levels. The reduction of this "splanchnic" utilization of ingested glucose may contribute to 
postprandial hyperglycemia: this defect has been observed in type 2 diabetics by some authors [13]. The splanchnic utilization of glucose appears to be increased in non-diabetic obese subjects, which may protect them from postprandial hyperglycemia [14]. Consistent with this hypothesis, hepatic glycogen content is increased in non-diabetic obese, and reduced in type 2 diabetics $[10,15]$. These data suggest that the methanolic extract of Ceiba pentandra may be used in case of hyperglycemia to enhance or restore the process of glycogen synthesis and reduce hepatic glucose production thus decreasing postprandial hyperglycemia. This in turn will have a positive impact on the glycation of biological molecules.

Glycation is a non-enzymatic reaction between reducing sugars and amino groups of proteins, lipids and nucleic acids. This process progresses at an accelerated rate under conditions such as hyperglycemia and/or oxidative stress [16]. Over time, these early-glycation products undergo other reactions such as rearrangements and dehydration to become fluorescent and crosslinked derivatives called advanced glycation end-products (AGEs) [17]. Inhibition of the formation of AGEs can be achieved through three mechanisms: (1) the inhibition of free radicals (2) the reduction of the level of reducing sugars (3) and the direct blocking of this reaction. For the first mechanism, Fofié et al. ([12] showed that Ceiba pentandra scavenge free radicals. As for the second mechanism, we have previously shown that extracts from Ceiba pentandra prevented hepatic production of glucose and stimulated its storage as glycogen. The next step was to determine the ability of the extracts to directly stop the glycation reaction. The results show that after 72 hours, the glycation of hemoglobin by fructose was significantly inhibited by the extracts with a greater effect noted with the methanolic extract (16\%). This inhibition induced by the extracts has a double importance. On the one hand, it prevents function alteration and toxic aggregation of glycation-modified proteins [18]. For example, modified glycated hemoglobin (an intermediate in the production of AGEs) has an increased affinity for oxygen over unmodified hemoglobin which can disrupt oxygen delivery to tissues (oxygen remains fixed on $\mathrm{Hb} 1 \mathrm{Ac}$ instead of being delivered to cells) and lead to hypoxia in severe cases of unbalanced diabetes [19]. On the other hand, this inhibition also blocks the formation of AGEs whose binding to RAGE receptors induces the production of pro-oxidants, pro-inflammatory cytokines and whose incidence has been observed in several pathological conditions such as diabetes, cardiovascular and neurological diseases [4].

\section{Conclusion}

The results of the present work show that the aqueous and methanolic extracts from the bark of Ceiba pentandra promote glucose tolerance through the stimulation of glycogen synthesis and inhibition of gluconeogenesis. Considering the importance of glycation in the genesis of cardiovascular complications associated with diabetes, Ceiba pentandra extracts can be used to directly inhibit this reaction which in turn will inhibit the formation of AGEs. These data, added to previous findings suggest that aqueous and methanol extracts from the stem bark of Ceiba pentandra are excellent therapeutic candidates for the remediation of diabetes and its associated dysfunctions.

\section{Acknowledgement}

The authors express their sincere gratitude to the Association of African Universities (AAU) and the C.V. Raman International Fellowship (No. INT/NAI/CVRF/2014) for their support.

\section{Competing interest}

The authors declare no conflict of interest associated with this work.

\section{References}

1. International Diabetes Federation. IDF DIABETES ATLAS Eighth edition 2017; [cited 2018 May 19]. Available from: http://www.diabetesatlas.org

2. Rizza RA (2000) Pathogenesis of fasting and postprandial hyperglycemia in type 2 diabetes: implications for therapy. Diabetes 59: 2697-2707. [Crossref]

3. Sharabi K, Tavares CDJ, Rines AK, Puigserver P (2015) Molecular pathophysiology of hepatic glucose production. Mol Aspects Med 46: 21-33. [Crossref]

4. Singh R, Barden A, Mori T, Beilin L (2001) Advanced glycation end-products: a review. Diabetologia 44: 129-146. [Crossref]

5. Fofie KC, Nguelefack-Mbuyo PE, Tsabang N, Kamanyi A, Nguelefack TB (2018) Hypoglycemic properties of the aqueous extract from the stem bark of Ceiba pentandra in dexamethasone-induced insulin resistant rats. Evid.-Based Complementary Altern. Med 1: 1-11.

6. Asgary S, Naderi GH, Sarrafzadegan N, Ghassemi N, Bosshtam M, et al. (1999) Antioxidant effect of flavonoids on haemoglobin glycosylation. Pharmaceutical Acta Helvetiae 1999; 77:223-226. [Crossref]

7. Adisa RA, Oke J, Olomu SA, Olorunsogo O (2004) Inhibition of human haemoglobin glycosylation by flavonoid containing leaf extract of Cnestis ferruginea. Journal of the Cameroon Academy of Sciences 4: 351-359.

8. EEC. Council directive 2010/63/EU, of the 22nd September 2010 on the approximation of laws, regulations and administrative provisions of the member states regarding the protection of animals used for experimental and other scientific purposes. Official Journal of the European Communities 2010; 1-29.

9. Satyaprakash RJ, Rajesh MS, Bhanumathy M, Harish MS, Shivanada TN, et al. (2013) Hypoglycemic and antihyperglycemic effect of Ceiba pentandra L. Gaertn in normal and streptozotocin-induced diabetic rats. Ghana Med J 47: 121-7. [Crossref]

10. Magnusson I, Rothman DL, Katz LD, Shulman RG, Shulman GI (1992) Increased rate of gluconeogenesis in type II diabetes mellitus. A $13 \mathrm{C}$ nuclear magnetic resonance study. J Clin Invest $90: 1323-1327$. [Crossref]

11. Pasieka AM, Rafacho A (2016) Impact of glucocorticoid excess on glucose tolerance: clinical and preclinical evidence. Metabolites 6: 24. [Crossref]

12. Fofie CK, Wansi SL, Nguelefack-Mbuyo EP, Atsamo AD, Watcho P, et al. (2014) In vitro anti-hyperglycemic and antioxidant properties of extracts from the stem bark of Ceiba pentandra. J Complement Integr Med 11: 185-193. [Crossref]

13. Ludvik B, Nolan JJ, Roberts A, Baloga J, Joyce M, et al. (1997) Evidence for decreased splanchnic glucose uptake after oral glucose administration in non-insulin-dependent diabetes mellitus. J Clin Invest 100: 2354-2361. [Crossref]

14. Ludvik B, Nolan JJ, Roberts A, Baloga J, Joyce M, et al. (1995) A noninvasive method to measure splanchnic glucose uptake after oral glucose administration. J Clin Invest 95: 2232-2238. [Crossref]

15. Muller C, Assimacopoulos-Jeannet F, Mosimann F, Schneiter P, Riou JP, et al. (1997) Endogenous glucose production, gluconeogenesis and liver glycogen concentration in obese nondiabetic patients. Diabetologia 40: 463-468. [Crossref]

16. Cho SJ, Roman G, Yeboah F, Konishi Y (2007) The road to advanced glycation end products: a mechanistic perspective. Curr Med Chem 14: 1653-1671. [Crossref]

17. Nowotny K, Jung T, Hohn A, Weber D, Grune T (2015) Advanced Glycation End Products and Oxidative Stress in Type 2 Diabetes Mellitus. Biomolecules 5: 194-222. [Crossref]

18. Nedic O, Rattan SIS, Grune T, Trougakos IP (2013) Molecular effects of advanced glycation end products on cell signalling pathways, ageing and pathophysiology. Free Radical Research 47: 28-38. [Crossref]

19. Demir I, Ermis C, Altunbas H, Balci MK (2001) Serum HbAlc levels and exercise capacity in diabetic patients. Jpn Heart J 42: 607-616. [Crossref]

Copyright: (C2018 Fofie KC. This is an open-access article distributed under the terms of the Creative Commons Attribution License, which permits unrestricted use, distribution, and reproduction in any medium, provided the original author and source are credited. 